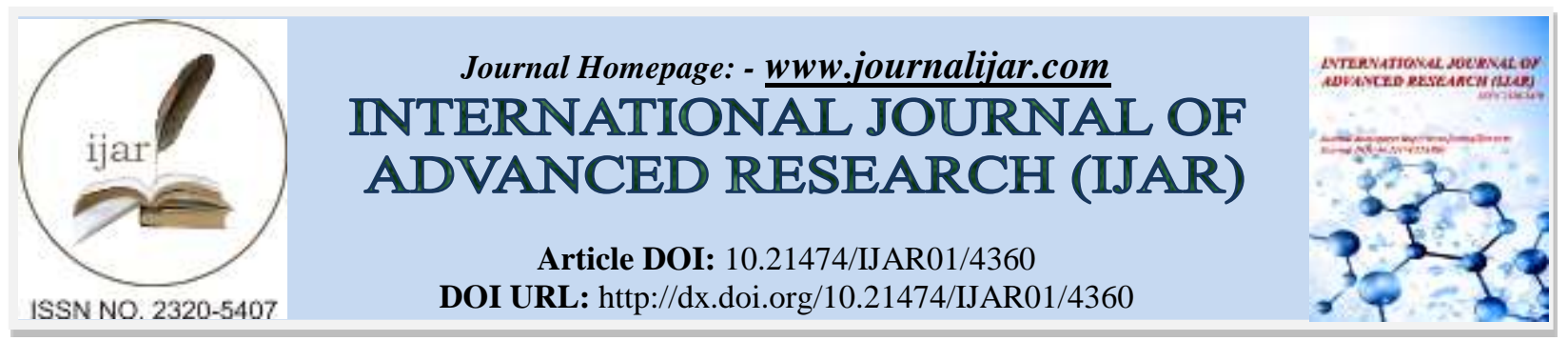

RESEARCH ARTICLE

\title{
PRO-TYPE MODELING OF SEISMIC STRUCTURE DESIGN (BASE ISOLATION AND BHATAR DESIGN)
}

Ankur Tayal.

Assistant professor, NIEC, GGSIPU New Delhi.

\section{Manuscript Info}

Manuscript History

Received: 29 March 2017

Final Accepted: 27 April 2017

Published: May 2017

Key words:-

Seismic , Isolation, Dissipation, Bhatar

Design , Bands

\section{Abstract}

The concept and aim of paper is to present a proto type model for design of seismic resistant design structure which has higher range of dissipating the seismic energy as compared to a normal design structure . In modern world it has been observed in metropolitan cities due to deficiency and high rates of land to design structure concept of floor system has been introduced. Each floor is design as separate component due to sale for a different customers. Now structure is constructed with various demands and requirements of customer for use which sometimes affects the homogeneity of entire structure . In such cases the specifications and design must be considered for single floor first in order to enhance the strength for entire building .

Copy Right, IJAR, 2016,. All rights reserved.

\section{Introduction:-}

The Paper presents the concept in pro-type Model form of a structural ground floor with Two Approaches i.e. Base Isolation and Bhatar Method (traditional method of structure design). The three components has been taken into consideration while designing i.e. the base foundation (a rectangular raft ), superstructure section consisting of walls - windows / doors / ventilators and other openings etc and the roof slab which completes a particular floor section or unit.

\footnotetext{
Aims and objectives:designing earthquake resistant structures. A main objective is to provide an effective linking of different parts of a building so as to enable them to work together and avoid the dislocation which causes collapse." consequently are more easily damaged.

Door and window openings :

1. Keep opening sizes small - $4 \mathrm{ft}$ wide maximum (stone walls $3 \mathrm{ft}$ wide).

2. Total length of openings should not exceed $50 \%$ of the wall length between cross walls.

3. 3. Always provide continuous lintel band and roof band.

4. Best to provide continuous sill band.

5. Distribute openings evenly around all sides of the building.

6. If this is not possible avoid putting all openings on one side only.
}

To construct buildings that have both flexibility and cohesion, is one of the most important considerations when

Regular shapes like square, rectangular and circular resist an earthquake more effectively as compared to irregular shapes. This is because during ground shaking the corner points of irregular shapes concentrate stress and 
If long and narrow buildings are built they should be divided into separate rooms rather than one long room. If this is not possible framing elements should be introduced.

\section{Proposed Work:-}

Approach -1: Foundation design with Rubber

The concept of earthquake protection of civil engineering structures by the use of rubber mountings of low shear stiffness has been discussed by Derham, Wootton, and Learoyd. taken from these references, shows the predicted response of a five-story shear-wall structure to an earthquake having a peak ground acceleration of $0.3 \mathrm{~g}$. The accelerations shown at the various mass levels have been computed both for the building with its foundation fixed conventionally, and for the building "floating" on natural rubber bearings. The bearing stiffness was such as to make the horizontal natural frequency of the mounted structure $0.5 \mathrm{~Hz}$. The basis of computation was the response spectrum of Housner. The results were later confirmed further by using a time-history analysis. The basic conclusion from these computer studies was that the use of rubber mountings leads the building to behave in an earthquake essentially as a rigid body. The rigid body accelerations, and hence the forces, are very much smaller than the accelerations experienced by a fixed-foundation structure, particularly in upper storys. For the case studied the overall maximum acceleration of the rubber-mounted structure was calculated to be one-tenth the maximum acceleration experienced by the fixed-foundation structure.

The proposed project also highlights the same use of natural rubber pads and bearings but installed in a different way. Here we are using a liquid rubber to enhance quality control of concrete. As the liquid rubber is sticky in nature therefore along with cement it contributes in improving interlocking and binding of concrete particles more strongly secondly along with rubber padding it forms a thin elastic layer to prevent deformations and deflections at subsequent levels as well keep the foundation protected from water problems.

The work includes a suitable design of cage of rubber pad like reinforcement cage bar which entraps the suitable reinforcement bars inside it and closed from above which is later filled with concrete having mixture of aggregates, sand ,cement and liquid rubber this forms a most stable part of structure and expected to increase more bearing and damping capacity for seismic waves.

\section{Base Isolation Analysis:-}

The base isolation analysis is composed of 4 steps:

\section{Step 1:-}

Isolation layer character estimation. confirm the design factors and the disposal, specification and number of rubber bearings of isolation layer can be estimated.

\section{Step 2:-}

Finite element analysis. The factors deduced from step 1 are regarded as the original factors, with the finite element analysis, we can get the natural vibration characteristics, inter-surface shear stress ratio, maximum displacement of isolation layer, bearing's carrying capacity of the structure

Step 3:- Comparing confirmation. Compare the computation results and verify the requirements of seismic design code.

Step 4:- Recursive computing analysis. If the comparison shows that the computation results can't meet the requirements and standards, the rubber isolation bearing factors need to be modified by the recursive calculation mentioned in step 2 and 3 until the results meet the desired standards. 


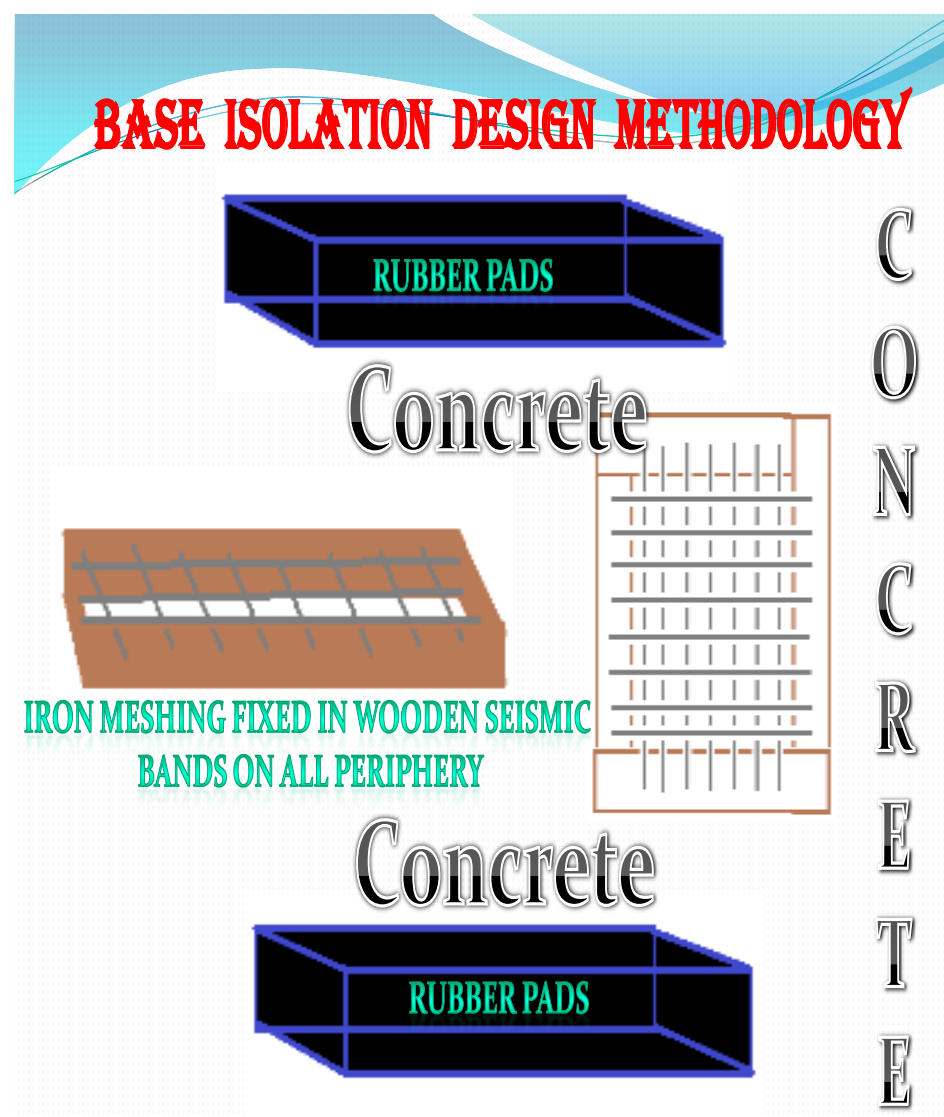

Fig.1:- Model designing of Sub structure by base isolation (Foundation level).

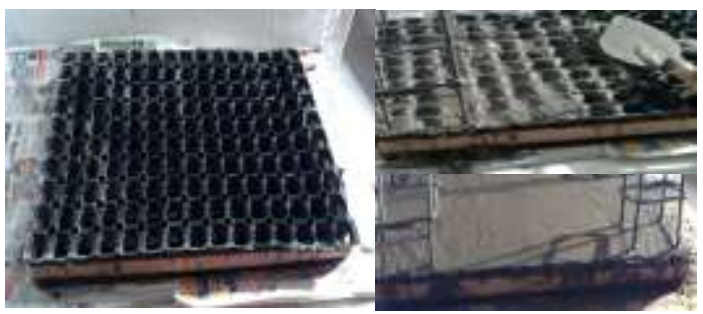

Fig. 2:- Rubber Isolated Fig.3. Concreting Base.

\section{Approach 2 -Bhatar Type Construction:-}

Timber bands (with cross pieces ) act as seismic bands which prevent the walls from falling apart in an earthquake .

Without bands, the structures stability is questionable. With bands walls of the structure held tightly. Seismic bands act as a belt to the structure.

Tradition method is adopted with stones but this project aims at performing the same method with use of bricks, this has following advantages :

Due to uniform dimensions of bricks structure becomes more reliable and active against earthquake.

$>$ Thickness of wall reduces hence availability of more space.

$>$ Structure has earthquake resisting seismic bands at its superstructure level also.

$>$ These seismic bands are more economic than present adopted techniques.

$>$ Dressing cost of stones and use of skilled labor is eliminated.

$>$ Timber reinforced masonry construction is traditional in parts of the affected area. 
$>$ Brick masonry reinforced with horizontal ladders (bands) to improve the integrity of the wall and to tie the walls together.

$>$ Brick masonry must be constructed with through brick and well packed, using flat or dressed bricks.

$>$ Timber bands are provided at regular intervals of $\max 2 \mathrm{ft}$.

$>$ Timber bands must have cross pieces at every $3 \mathrm{ft}$ horizontally and good joints and overlapping.

$>$ Confined masonry consists of load bearing brick or block masonry or in situ concrete panels surrounded by horizontal and vertical ,confiningee elements made from reinforced concrete.

$>$ Wall panels are built first and then the reinforced concrete columns poured afterwards. The wall should be built with toothing to ensure a good connection with the concrete column.

$>$ Walls should also be tied to columns with horizontal reinforcement.

\section{Basic rules:-}

- No walls must be longer than 12 feet without being connected to another wall.

- Openings should be minimum 3 feet from corners or other opening.

- Windows must be smaller than 3 feet.

- Walls must be maximum 18 inches thick.

- Walls must not be higher than 10 feet.

- Use blue pin or Cedar for the beam.

- Use galvanized nails (with zinc layer) for all work except inside the house (so they do not rush).

- Use flat or dressed stones for your masonry. Don't use round rubbles.

- All walls must be connected to each other with proper stone masonry and timber beams.

- $\quad$ Place through stones every two feet. They make the wall stronger.

- The timber beam act as 'seismic band'. A seismic band must be continuous, like a loop or a belt. Seismic bands should always be continuous; an offset in elevation is not acceptable.

- $\quad$ RC seismic bands should always remain level without any dips or changes in height.

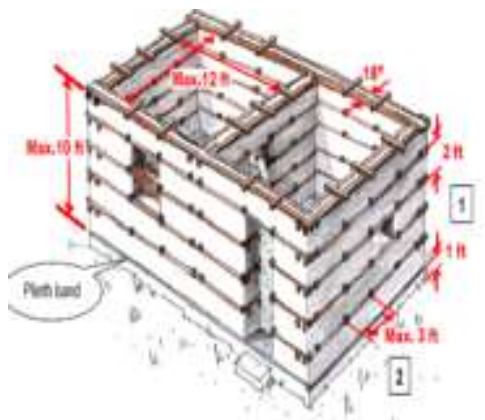

Fig 4:- Schematic Top View of Bhatar Design Model.
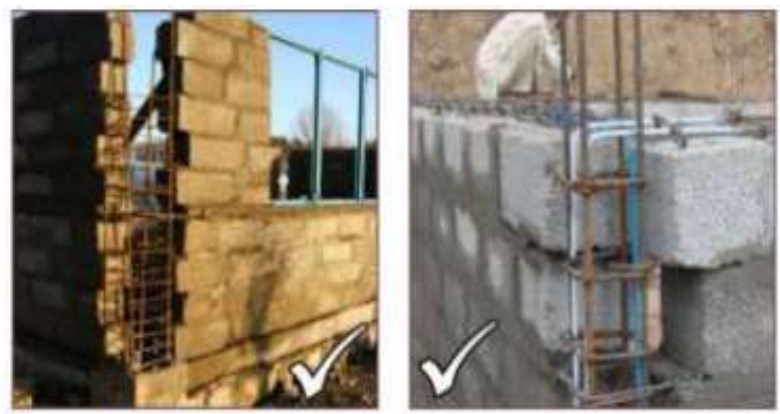

(a) (b)

Fig 5:- (a) Modified design Of Bhatar technique by use of modern bricks 4(b) Design Specifications For Bhatar Method 


\section{Protype Images for Sections:-} Section 1 - Base foundation:-

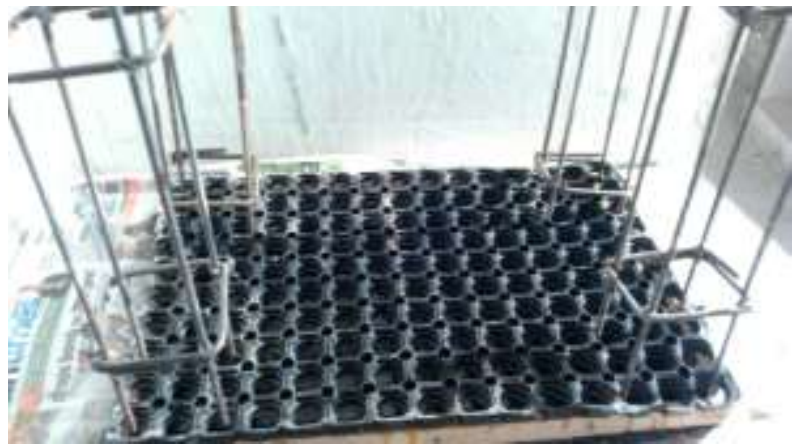

Fig. 6:- Design and Construction of Isolate Base.

Section 2:- Superstructure - Bhatar Method for walls and openings doors, windows etc

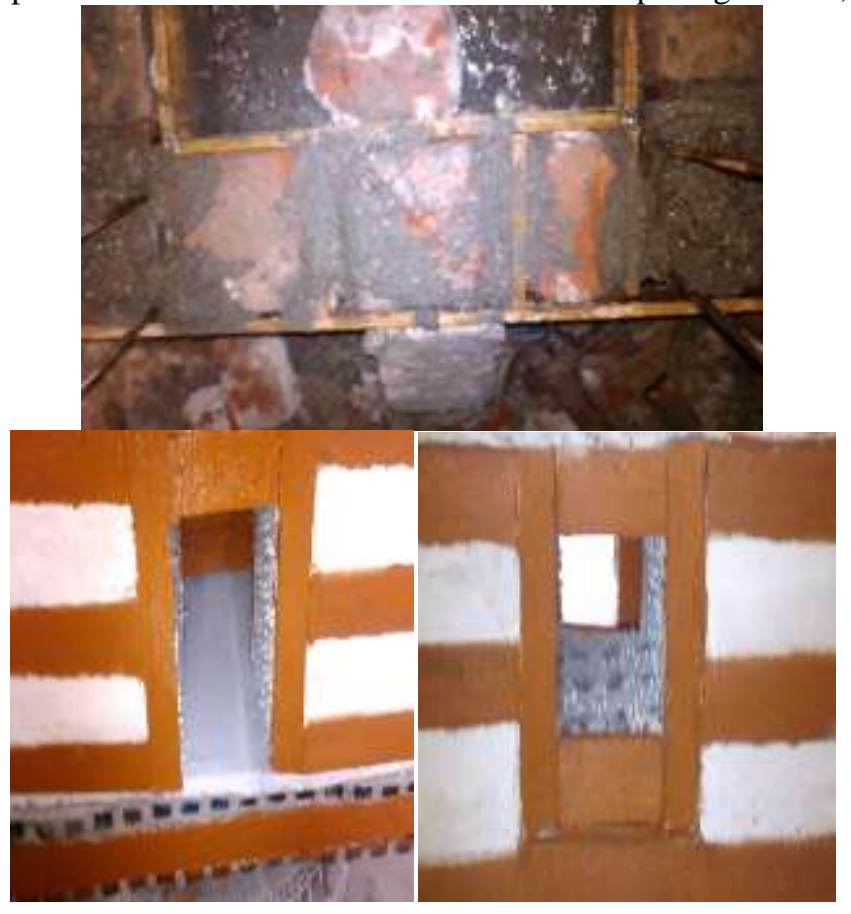

Fig.7:- Installing Bhatar specifications on walls columns and bindings Section 3 - Top Roof Slab

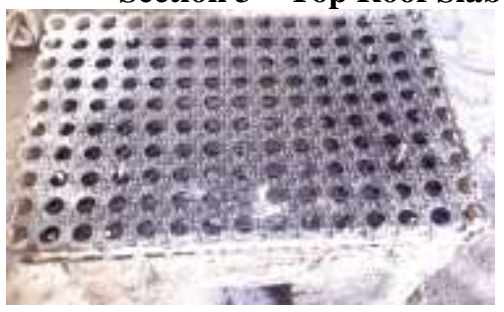




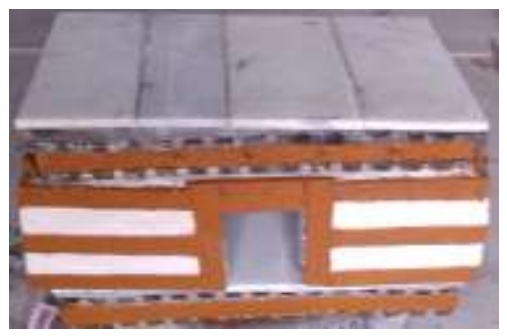

Fig. 8:- Roof slab with rubber isolation to dissipate seismic energy at various storey level.

\section{Scope of the proposed work:-}

The Proposed work involves a great scope for present and future demands against fighting the earthquake conditions. This work not only proves economic but also targets at sustainable development. This not only involves designing at foundation level but also have scope and considerations at superstructure level.

Key points are Discussed as Follows:-

$>$ Damping of vibrations at base or foundation level by base isolation method(90\%) Laying Down of each roof slab by sandwiching the concrete between rubber padings.

$>$ Use of traditional BHATAR method but with Bricks for holding the structure in erect position by use of seismic bands against the effect of remaining waves not completely damped at base level

$>$ Dividing the structure into units where an unit comprise of particular no. of floors as per design considerations

Target issues of project:-

Quantum change and transferability:-

Appropriate from social, cultural and ecological point of view and have a brought a culture of safe buildings in combination of modern techniques. This also provides response to local needs and capacities. By identifying and reinvigorating traditional know how a safer building with local capacities and resources can be ensured and getting a seismic officially culture recognized by national authorities

\section{Ethical standards and social equity:-}

To use of government subsidies to rebuild houses instead of wasting funds on transport and other practices is the main role.

Getting the culture recognized and respected gives a privilege in contributing in national building

- Ecological Quality and energy conservation Use of locally available and renewable resources, unnecessary transport , ecological quality and energy conservation are greatly improved. This bhatar method construction provides thermal insulation than modern simple houses providing further energy savings.

- Economic performance and compatibility Wood is a material that is available ;locally so further maintainence can be done whenever needed by using the local resources available and avoiding excessive costly degradation of the building

- Contextual and aesthetic impact

use of traditional building material secures the aesthetic coherence of building environment. Structural design can be used in appropriate way for the purposes of aesthetic and inbuilt stability is also maintained.

\section{References:-}

1. www.nicee.org/iaee/E_Chapter3

2. www.iitk.ac.in/nicee/wcee/article/vol.3_session4_1917

3. www.holcimfoundation.org/.../advocacy-of-traditional-earthquake-resistant design

4. www.scribd.com/doc/91538503/Final-Project-Report-of-Base-Isolation

5. https://law.resource.org/pub/in/bis/S03/is.4326.1993

6. https://law.resource.org/pub/in/bis/S03/is.1893.1.2002 